\title{
Biosynthesis of Cellulose by Acetobacter Xylinum. I. Characterizations of Bacterial Cellulose
}

\author{
Mitsuo TakaI, Yasushi Tsuta, and Sadayoshi Watanabe \\ Department of Applied Chemistry, Faculty of Engineering, \\ Hokkaido University, Sapporo, Hokkaido 060, Japan.
}

(Received December 26, 1973)

\begin{abstract}
The addition of a small amount of ethyl alcohol into the culture (0.5-\% yeast extract and $2 . \%$ glucose; $\mathrm{pH} 5.9)$ resulted in a fast rate of multiplication of Acetobacter Xylinum. Cells metabolized glucose for two days forming a mat of cellulose microfibrils on the surface of the solution. It was a tough membrane which could not be torn easily. The product free from cells is as typical a native cellulose as cotton by $\mathrm{X}$-ray analysis, but shows a preferential orienting tendency. $\overline{\mathrm{DP}}$ of bacterial cellulose by the cupro-ammonium method was 5700 , comparable to the value of ramie cellulose. Bacterial cellulose has more accessible parts for hydrochloric acid than ramie or Valonia cellulose. The mercerization process to prevent shrinkage of an undried bacterial cellulose membrane tends to produce a biaxially oriented sheet of regenerated cellulose. It was recognized that a preferential orientation of crystallites in bacterial cellulose affects the fine structures of heterogeneously acetylated and nitrated products. They are still available for the crystalline structural study of cellulose triacetate and trinitrate.
\end{abstract}

KEY WORDS Acetobacter Xylinum / Cell / Bacterial Cellulose / Culture / Preferential Orientation / Crystallite Width / Acid Hydrolysis / Mercerization / Acetylation / Nitration /

Although cellulose is a compound of qualitative importance as a skeletal material, the most abundant and widely used natural plant product, the mechanism by which cellulose microfibrils are formed is far from known. Recently we have been engaged in the molecular mechanism for formation of the cellulose microfibril. Several structural problems of cellulose have been as simple conceptually as the problem of whether neighboring chains in the native cellulose microfibril run in the same or opposite directions (i.e., whether the chain orientation is parallel or antiparallel). Many models of chain folding in cellulose have been proposed among which those of Ellefsen ${ }^{1}$ and Manley ${ }^{2}$ are the forerunners. However, none of these have been widely accepted as a successor to the fringed micellar model.

Much more work is necessary before the problem can be discussed in detail profitably.

As long ago as 1886 A. J. Brown ${ }^{3}$ described a bacterium which produced a solid membrane when growing on a carbohydrate rich medium. Later investigation by Hibbert ${ }^{4}$ demonstrated that the membrane is indeed cellulose. Mark and Susich $^{5}$ confirmed the identity of bacterial cellulose with cotton cellulose by producing well oriented diagrams from stretched membranes that were the same as those from cotton.

In the present study the culture conditions were preliminarily examined to prepare bacterial cells and membranes. Subsequently the bacterial cellulose membranes were characterized by X-ray diffraction and the absorption of infrared radiation. Their chemical reactions, such as acetylation, nitration, mercerization and acid hydrolysis, were also examined.

\section{MATERIALS AND METHODS}

\section{Preparation of Bacterial Cells and Membranes}

Strain AHU-1595 of Acetobacter Xylinum was obtained from Applied Microbiological Laboratory, Department of Agriculture Chemistry, Faculty of Agriculture, Hokkaido University, through the courtesy of Drs. T. Sasaki and S. Takao. At first a suspension of whole cells free from 
cellulose in sterilized substrate was prepared. One $\mathrm{m} l$ of this solution was inoculated into $200-\mathrm{m} l$ of liquid medium $(0.5-\%$ yeast extract and $2-\%$ glucose; $\mathrm{pH} 5.9$ ) in a smooth walled $500 \mathrm{~m} l$ shaken flask, and then incubated in both static and shaken cultures at $30^{\circ} \mathrm{C}$ and harvested after various periods of time. Membranes in a highly swollen or gel condition were taken from the surface of the cell suspension, collected on layers of cotton gauze and washed with distilled water to remove water-soluble materials. They were then immersed in $2-\% \mathrm{NaOH}$ solution to remove alkali-soluble components and washed with distilled water until neutral to phenolphtalein. Cellulose residues were immersed in cold $1-\%$ acetic acid to neutralize the last traces of alkali. Finally they were washed exhaustively with large volumes of distilled water and dried at $105^{\circ} \mathrm{C}$ in an air oven until a constant weight was reached.

\section{Method for Estimation of Polymerization of Cellu- lose}

Fifty $\mathrm{mg}$ of the cellulosic prodoct was dissolved in $10 \mathrm{ml}$ of cupro-ammonium solution, homogenized as much as possible by stroke shaking, and maintained in a thermostat at $20^{\circ} \mathrm{C}$. Specific viscosity was measured by an Ohken's viscometer (developed in the Laboratory of Ohji Paper Industry Inc.) with a flow-time of $35 \mathrm{sec}$ for the pure solvent (10-m $l$ solvent volume). The average polymerization of the cellulose was caluculated from Staudinger's formula with a constant of $K_{\mathrm{m}}$, $5 \times 10^{-4}$. The gel permiation chromatographic patterns of the nitrated cellulose were also observed.

\section{Methods for Acetylation, Nitration, Mercerization, and Acid Hydrolysis of Cellulose}

Heterogeneous acetylation involved pretreating the cellulose materials in glacial acetic acid at $30^{\circ} \mathrm{C}$ for $24 \mathrm{hr}$ or in an aqueous solution of $40-\%$ potassium acetate at $50^{\circ} \mathrm{C}$ for $1 \mathrm{hr}$. Then the cellulosic materials were acetylated by using 25 parts of acetic anhydride and 75 parts of benzene at $30^{\circ} \mathrm{C}$ for $48 \mathrm{hr}$ with nascent sulfonic acetic acid as a catalyst. The products were washed with benzene until free from acid and then immersed in $75-\%$ neutralized ethyl alcohol at $50^{\circ} \mathrm{C}$ for $1 \mathrm{hr}$ to remove sulfonic acetic acid thoroughly. Finally they were washed exhaustively with dis- tilled water. To recrystallize the product it was heat treated with silicone oil (KF-54, Shinetsu Chem. Prod. Inc.) at $210^{\circ} \mathrm{C}$ for $15 \mathrm{~min}$. The acetylated products crystallized in this way were used for X-ray analysis.

The nitration of cellulose was carried out by the following three types of mixed acid: $\mathrm{H}_{2} \mathrm{SO}_{4}-\mathrm{HNO}_{3}$; in a weight ratio of $3 / 1$, and nitrated at $0^{\circ} \mathrm{C}$ for $24 \mathrm{hr}$, (2) $\mathrm{AcOH}-(\mathrm{Ac})_{2} \mathrm{O}-$ $\mathrm{HNO}_{3}$; in a weight ratio of $9: 7: 13$ and before nitration, celluloses were pretreated with glacial acetic acid at $20^{\circ} \mathrm{C}$ for $24 \mathrm{hr}$ and then reacted in the above mixed acid at $0^{\circ} \mathrm{C}$ for $2 \mathrm{hr}$, (3) $\mathrm{H}_{3} \mathrm{PO}_{4}-\mathrm{HNO}_{3}$; in a weight ratio of $4 / 6$ and nitrated at $0^{\circ} \mathrm{C}$ for $1 \mathrm{hr}$. After nitration each product was washed exhaustively with distilled water until the wash water no longer indicate an acidity to methyl orange, and dried at room temperature in a vacuum desiccator containing phosphorus pentoxide. The nitrated products were recrystallized with superheated steam in microautoclave at $150^{\circ} \mathrm{C}$ for $1 \mathrm{hr}$ and subjected to X-ray analysis. The nitrated product from mixed acid (1) is the most heterogeneous one. The nitration by (3) is more homogeneous than that by (2) and could give a highly nitrated products without a degradation of the original polymers. Therefore, the nitration by (3) is the most profitable for gel-permiation-chromatographic(GPC) measurements.

The action of sodium hydroxide, e.g. mercerization, for bacterial cellulose was observed in the following two ways. One was that water of the swollen, undried membranes was substituted with 18-\% sodium hydroxide. The other was that the membrane was first dried on a glass plate and then treated with sodium hydroxide. These two specimens of membranes were subjected to X-ray analysis.

The cellulose materials were hydrolyzed in constant boiling 2.4- $N$ hydrochloric acid by refluxing for various periods of time. After hydrolysis the residues were filtered through sintered glass with an average pore size of $40 \mu$ followed by washing with ethanol to prevent formation of a honey-like mass upon drying. The products then were dried to constant weight at room temperature in a vacuum desiccator containing phosphorus pentoxide. They were subjected to viscometric analysis for estimation 
Biosynthesis of Cellulose by Acetobacter Xylinum. I.

of polymerization.

Methods for X-Ray Diffraction and Estimation of the Crystallite Size of Cellulose

The general fiber diffractograms with the X-ray beam perpendicular and parallel to the surface of the dried membrane were obtained by a flat film camera with nickel-filtered $\mathrm{CuK} \alpha$ radiation of Rigaku Denki High Power Rota Unit $3 \mathrm{~V}$ system. An X-ray diffractometer trace of the membrane was obtained by the reflection method with Rigaku Denki automatic diffractometer operated in the $\omega-2 \theta$ scanning mode between $10^{\circ}$ and $30^{\circ}(2 \theta)$. The flat surface of the membrane was set parallel to the reflecting surface. Slits of $1^{\circ}$ and $0.2 \mathrm{~mm}$ for the tube and detector, respectively, were used.

The crystallite sizes of cellulose could be obtained from the line breadth of the (101) and (002) interferences. The usual Sherrer formula was employed, $D=0.9 \lambda / \beta \cdot \cos \theta$, where $D$ is crystallite size in $\AA, \lambda$ the wave length in $\AA$ of the X-ray used $(\mathrm{CuK} \alpha 1.5418 \AA), \theta$ the Bragg angle in degrees, and $\beta=\left(B^{2}-B_{0}{ }^{2}\right)^{1 / 2}$, with $B$ the half breadths of interferences, $B_{0}$ the instrumental broadening, respectively, in rad. The effect of instrumental broadening can be assessed in $\beta$ by measuring the widths of lines from large undistorted crystals under identical operating geometries. For silicon and $\alpha$-quartz, the instrumental broadening amounted to $0.11^{\circ}(0.00192$ $\mathrm{rad})$. The broadening due to instrumental factors can be rigorously removed by the correction of square rooted mean according to the profile of approximate Gaussian distribution.

\section{RESULTS AND DISCUSSION}

\section{Characterization of Bacterial Cellulose}

Gel Permiation Chromatograms. Figure 1 shows GPC patterns of (A) undried and (B) dried bacterial cellulose membranes subjected to nitration (with $\mathrm{H}_{3} \mathrm{PO}_{4}-\mathrm{HNO}_{3}$ ). They differ from each other in their distribution. The pattern of the undried membrane is distributed in the slightly smaller molecular region, probably due to a degradation during the course of nitration. The GPC of prehydrolyzed cellulose with $2.4-N \mathrm{HCl}$ gave a more narrow distribution pattern (Figure 2). Furthermore, the peak for the distribution

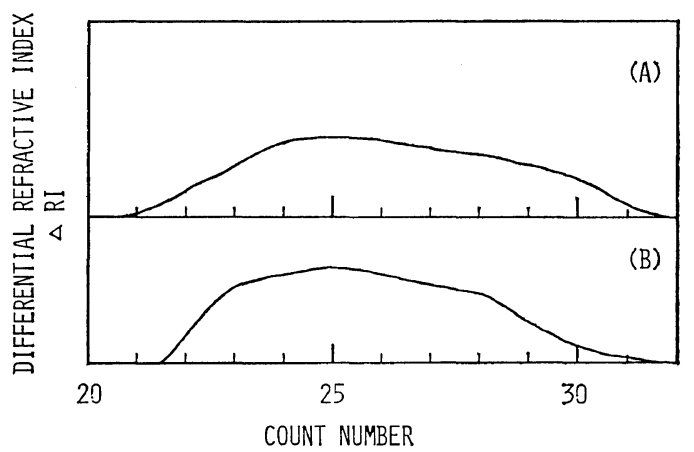

Figure 1. The gel permiation chromatograms of (A) undried and (B) dried bacterial cellulose membranes.

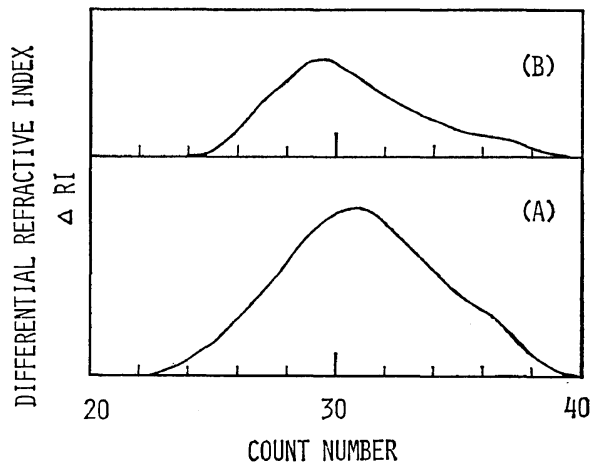

Figure 2. The gel permiation chromatograms of (A) prehydrolyzed bacterial cellulose compared with (B) that of ramie cellulose.

is shifted to a higher count side, i.e., to a lower molecular size region. This peak corresponded to a $\overrightarrow{\mathrm{DP}}=330$ of glucosidic units, which was calibrated with polystyrene as a standard. The pattern showed a discernible shoulder on the lower molecular side, corresponding to a $\overline{\mathrm{DP}}=$ 40. The overall results as noted above, are also characteristic for the hydrolysis of other native celluloses. They seem to have a fundamental significance for elucidating the fine structure of cellulose.

The Levelling off of Degrees of Polymerization by Acid Hydrolysis. Results of the viscometric analysis of average degree of polymerization of bacterial cellulose compared with two other sources, i.e., ramie and Valonia celluloses, are shown in Table I. Generally speaking, the $\overline{\mathrm{DP}}$ of cellulose decreases remarkably with increasing 
Table I. Column (A): The viscometric average degree of polymerization of bacterial, Valonia, and ramie celluloses. Column (B): The levelling off degrees of polymerization of them prehydrolyzed by $2.4 \mathrm{~N}$ hydrochloric acid for $1 \mathrm{hr}$ at $100^{\circ} \mathrm{C}$.

\begin{tabular}{lrr}
\hline Cellulosic sources & $(\mathrm{A})$ & $(\mathrm{B})$ \\
\hline Bacterial & 5700 & 230 \\
Valonia & 38000 & 7000 \\
Ramie & 4000 & 200 \\
\hline
\end{tabular}

duration of hydrolysis, becoming constant upon a continued hydrolysis of the sample. The constant value for the $\overline{\mathrm{DP}}$ is defined as the levelling off degree of polymerization (LODP). The $\overline{\mathrm{DP}}$ of bacterial cellulose before hydrolysis was 5700 , comparable to the value of ramie cellulose. However, it differs extraodinarily from that of Valonia cellulose. Such a difference was also observed in the LODP of hydrolyzed cellulose. These corresponded to the GPC results respectively. Therefore, the results from the LODP appear to reflect the characteristic fine structure of cellulose.

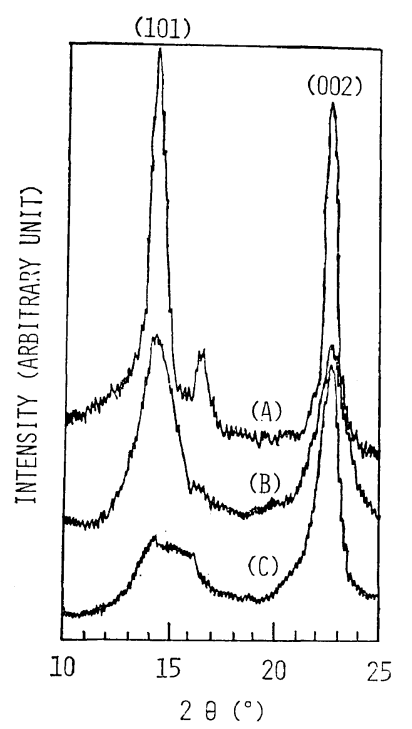

Figure 3. X-ray diffractograms of (A) Valonia, (B) bacterial, and (C) ramie celluloses by the reflection method. The membranous specimens were dried with a flat surface of membranes parallel a glass plate, and set parallel to the reflecting surface.
$X$-Ray Diffraction Patterns. In Figure 3 are shown X-ray diffractograms of bacterial, Valonia, and ramie celluloses. In bacterial and Valonia celluloses, the intensity of an interference indexed in the (101) plane is equivalent with or higher than that of the (002) plane. The interference of the $(10 \overline{1})$ plane is almost diminished in this way, but it occurred in the azimuthal direction of the X-ray photograph with the beam irradiated parallel to the flat surface of specimens. They result in a preferential orientation, i.e., selective uniplanar orientation with respect to the membrane surface for both bacterial and Valonia celluloses. The preferential orientation of bacterial cellulose will be discussed more in detail in part III of this study. On the other hand, the crystallinity of each cellulose increases in the order of ramie, bacterial, and Valonia celluloses. This order is essentially the same as that observed by Hermans ${ }^{6}$. The crystallite size of bacterial cellulose is $55 \AA$ in breadth which is calculated from a half breadth of the (002) interference. This is the same as that of ramie, but differs from that of Valonia, $130 \AA$. All of them are in disagreement with the results obtained from the electron microscopic measurements of microfibril breadths. Recently high-magnification photographs of negatively stained, ultrasonically treated microfibrils from ramie, cotton, wood, Valonia and bacterial celluloses show filaments having a breadth $c a .35 \AA$ $(7,8,9,10)$. The opposing view is that the elementary microfibril can be much larger (in some cases over $100 \AA$ ) and that the constant $35 \AA$ measurement is the result of an artifact $(11,12)$. Evidence of large structures is then suggested as resulting from a lateral coherence of a number of elementary fibrils. This coherence is inferred to occur during the drying process. The mechanism for this type of coherence, whereby the paracrystalline surfaces of the smaller units become incorporated into a perfected crystalline lattice, must then be explained.

IR Spectra. Infrared spectra were obtained with a Hitachi EPI-G2 spectrophotometer by use of the potassium bromide pellet technique for fiberous samples and direct use of the film for the membranes.

From a structural point of view, the most interesting part of the cellulose infrared (IR) spectrum is the $3 \mu\left(3350 \mathrm{~cm}^{-1}\right)$ region. Here 
Biosynthesis of Cellulose by Acetobacter Xylinum. I.



Figure 4. The IR absorption spectra of native celluloses in the 3- $\mu$ region: (A) Valonia cellulose; (B) bacterial cellulose by direct use of the thin film for membranes; (C) ramie cellulose by a $\mathrm{KBr}$ pellet technique.

(see Figure 4) we observed the IR spectra of three sources of native cellulose, ramie, Valonia macrophysa and bacterial celluloses. In its simplest possible interpretation the infrared spectrum of crystalline cellulose might be expected to show the same number of $\mathrm{O}-\mathrm{H}$ stretching modes as there are $\mathrm{OH}$ groups per asymmetric unit. A more thorough approach would consider the entire unit cell, or possible "in-phase" and "out-ofphase" combination vibrations between $\mathrm{OH}$ groups that are related by a two-fold screw axis in a crystallographic sense. However, experience with cellulose in the $\mathrm{O}-\mathrm{H}$ stretching region has shown that we observe a smaller number of bands than any theoretical prediction would make, and the logical interpretation as this time is semiempirical. From a knowledge of the most pro- bable chain conformation, unit cell dimensions, and approximate position of the residues in the unit cell one attempts to relate the observed $\mathrm{O}-\mathrm{H}$ stretching bands to intramolecular and intermolecular hydrogen-bond arrangements, with acceptable dichroisms and bond lengths. The effect of crystalline order is evident in Figure 4 if one compares the spectrum of ramie with that of a membrane from Valonia macrophysa or bacterial cellulose, since the latter two are known to be more crystalline than the former. The spectral differences are sufficiently characteristic in this region for identification Marrinan and $M a n n^{13}$ refer to spectra from Valonia and bacterial celluloses as type $\mathrm{A}$ and to that from ramie as type B. Significantly, Valonia is characterized by a unit cell with four times the base plane area of the usual cellulose $I$ unit cell ${ }^{14,15}$. In keeping with this greater order, six fairly well defined $\mathbf{O}-\mathbf{H}$ stretching bands are found for Valonia and bacterial celluloses, whereas only five bands are clearly resolved in the ramie cellulose. The overall aspect of the absorption by the latter is less well defined. The absence of absorption near $3650 \mathrm{~cm}^{-1}$ indicates that there are no free hydroxyls in solid cellulose. Therefore, all assignments must be in terms of hydrogen-
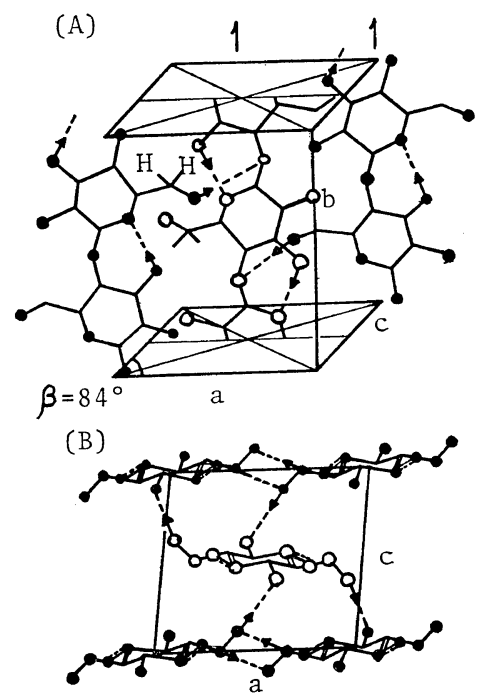

Figure 5. The hydrogen-bonding scheme for cellulose I proposed by Liang and Marchessault. The unit cell is viewed (A) perpendicular the $a b$-plane, (B) along the fiber axis. 
bonded groups. At this time, the Liang and Marchessault $^{16}$ assignments for cellulose I and the hydroxymethyl $\left(-\mathrm{CH}_{2} \mathrm{OH}\right)$ conformation equivalent to that for cellobiose ${ }^{17,18}$ appear to be most reasonable. Native cellulose membranes, such as Valonia cell walls, have a pronounced selective uniplanar orientation in that the (101) planes are preferentially parallel to the membrane surface. This led Frey-Wyssling to suggest that the forces holding the chains together in this plane were stronger than those in the almost perpendicular $(10 \overline{1})$ planes. It was noted that if the $-\mathrm{CH}_{2} \mathrm{OH}$ groups were involved in intermolecular hydrogen bonding to the glycosidic or bridge oxygen, these bonds would be approximately parallel to the (101) or (101) planes. Since the monoclinic unit cell is not rectangular, hydrogen bonds in the (101) planes must be shorter and therefore stronger than those in the $(10 \overline{1})$ planes. The chain in the center of the unit cell (Figure 5) has been shifted along the fiber axis by about one-half a glucose unit in order to bring the ring oxygen to a suitablep osition

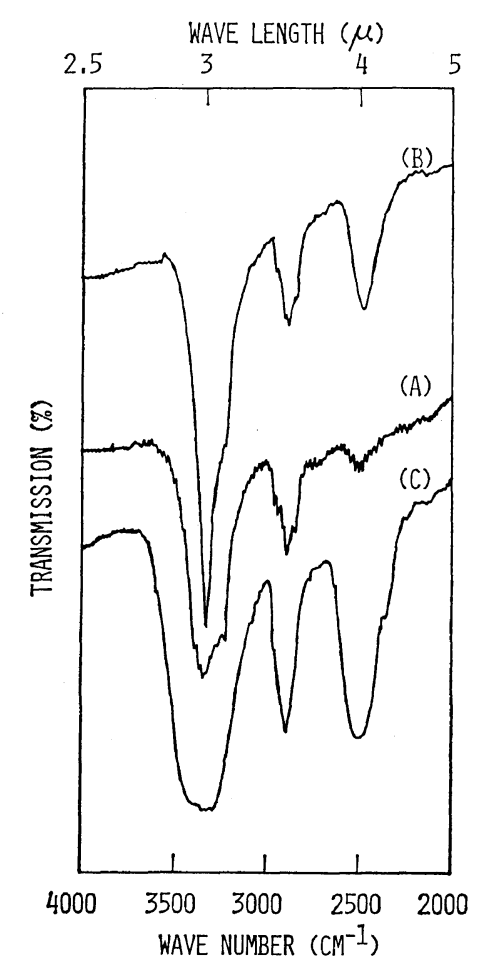

Figure 6. The IR absorption spectra of deuterated (A) Valonia, (B) bacterial, and (C) ramie celluloses. relative to the hydroxymethyl groups of the corner chains. This type of translation also gave the best agreement between the calculated and observed X-ray intensity ratio for the meridional reflection. ${ }^{19}$

It should be borne in mind that infrared analysis in combination with substitution of deutereium for hydrogen atoms has been used successfully for quantitative determination of the "crystallinity" and "accessibility" of various cellulose preparations. A quantitative study which "enables the crystallinity of a cellulose, defined as the fraction of $\mathrm{OH}$ groups which are hydrogen bonded in a regular crystalline manner, to be estimated by infrared spectroscopy" was published by Mann and Marrinan. ${ }^{20}$ The relative intensities of the OD- and OH-stretching bands were used to calculate the fraction of hydroxyl groups which were inaccessible to deuterium exchange. Each cellulose was moistened with deuterium oxide to exchange the accessible hydroxyl hydrogens with deuterium and then dried. The presence of sharp absorption bands in the $2400-2650 \mathrm{~cm}^{-1}$ region of the infrared spectra (O-D stretching) is shown in Figure 6. The ratio of $\mathrm{OD}$ - to $\mathrm{OH}$-stretching indicates one of the accessibility indices of cellulose. The indices are 0.046 for Valonia, 0.261 for bacterial, and 0.480 for ramie celluloses. This order is the same as the crystallinity obtained by X-ray analysis.

For the $\mathrm{C}-\mathrm{H}$ stretching vibrations the general consideration is that there is little or no interaction between the vibrations of neighboring residues, and therefore it may be adequate to examine the predicted bands for a single residue; that is, five bands from the stretching of the five $\mathrm{CH}$ groups and two from the symmetrical and antisymmetric stretching modes of the $\mathrm{CH}_{2}$ groups per glucose residue. We resolved six bands in this region for Valonia and bacterial celluloses and five bands for ramie cellulose. The ramie specimen was not as crystalline nor as well orientated as the first two materials, which probably accounts for the difference.

The band at $1430 \mathrm{~cm}^{-1}$ can be assigned to the $\mathrm{CH}_{2}$ symmetric deformation mode (Figure 7). These spectra have characteristic appearance that allows its "fingerprinting" as a polysaccharide. Of the strong bands between 1200 and $1000 \mathrm{~cm}^{-1}$, 
the one at $1160 \mathrm{~cm}^{-1}$ has been assigned to the antisymmetric bridge $\mathrm{C}-\mathrm{O}-\mathrm{C}$ stretching. Similar bands at this frequency are observed for the

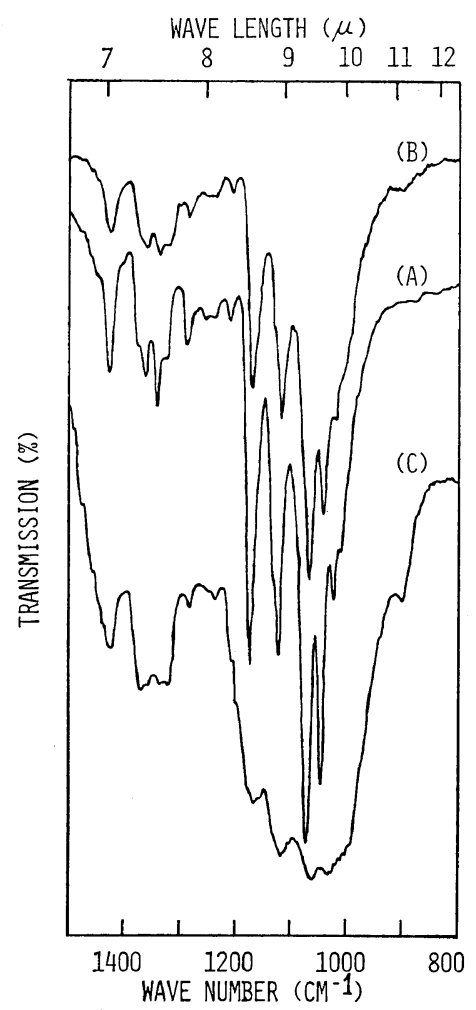

Figure 7. The IR absorption spectra of native celluloses in the $7-12-\mu$ region: (A) Valonia; (B) bacterial; (C) ramie celluloses.

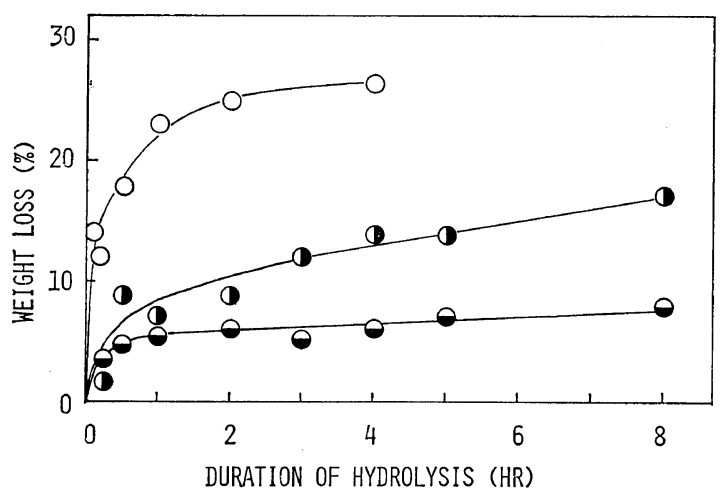

Figure 8. Effect of prolonged heterogeneous hydrolysis $\left(2.4 \mathrm{~N}-\mathrm{HCl}, 100^{\circ} \mathrm{C}\right)$ on weight loss of native celluloses: $\odot$, Valonia; $\bigcirc$, bacterial; $O$, ramie celluloses. chitins and for amyloses and xylans; it appears to be typical of many polysaccharides. The bands at $1110 \mathrm{~cm}^{-1}$ and $895 \mathrm{~cm}^{-1}$ can be assigned to the antisymmetric in phase and out of phase ring stretching, respectively.

Acid Hydrolysis, Mercerization, Acetylation and Nitration of Bacterial Cellulose. It should be borne in mind that the heterogeneous acid hydrolysis of cellulose has been used often for quantitative determination of the "accessibility" and "crystallinity" of various cellulose preparations, and usually compared with the infrared analysis in combination with substitution of deuterium for hydrogen atoms. Figure 8 shows the fractional weight loss of cellulose materials versus duration of acid hydrolysis. In the early stage from 10 to $60 \mathrm{~min}$ of acid hydrolysis, the

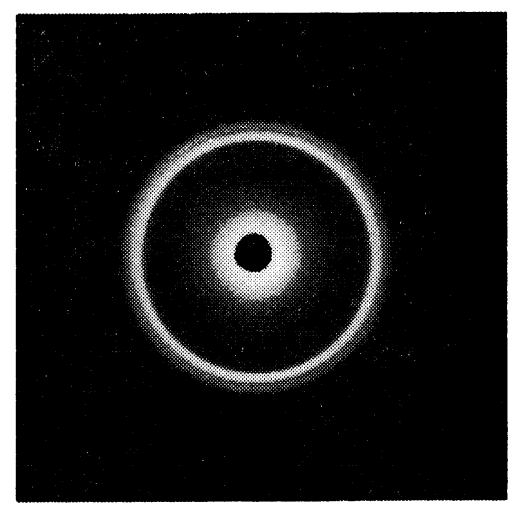

(A)

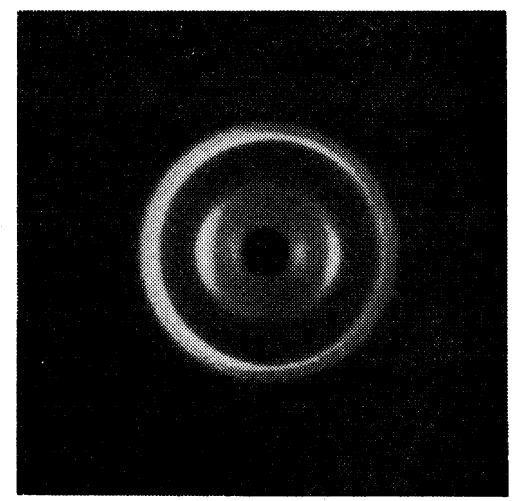

(B)

Figure 9. X-ray photographs of mercerized bacterial cellulose allowed to contact freely upon mercerization; X-rays (A) perpendicular to and (B) parallel to the surface of the membranes. 
weight loss curves increased logarithmically, whereas after $2 \mathrm{hr}$ they increased linearly with the duration of hydrolysis. In general the accessibility of cellulose to be estimated by acid hydrolysis is defined as the weight loss of cellulose material which results from extrapolating the linear stage of the curves to find their points of intersection. The accessibilities by such a method are $11.7 \%$ for bacterial cellulose, $4.6 \%$ for ramie cellulose, and $2.6 \%$ for Valonia cellulose. This indicates that bacterial cellulose has more accessible parts for a mineral acid, that is, more "amorphous parts," than ramie or Valonia cellulose. The order in the accessibilities is different from that in the crystallinities obtained by X-ray analysis and in the accessibilities by IR. This may be

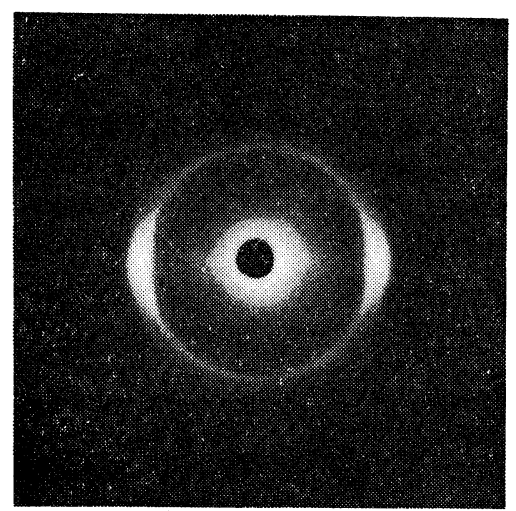

(A)

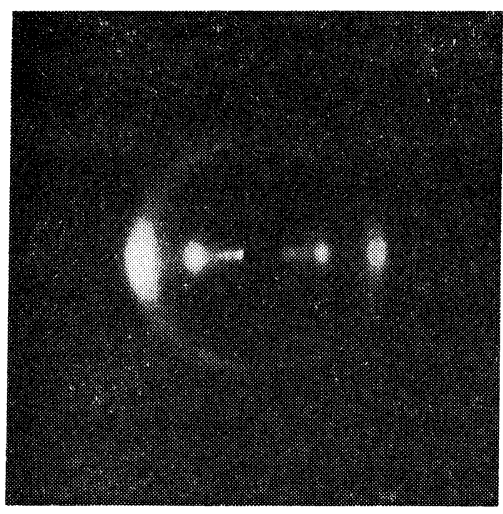

(B)

Figure 10. X-ray photographs of mercerized bacterial cellulose clampled to a glass plate to prevent the shrinkage from occurring by mercerization; X-rays (A) perpendicular to and (B) parallel to the surface of the membranes. due to a drying condition of bacterial cellulose membranes swollen with water.

While studying the effect of substituting other liquids for water in the swollen bacterial cellulose membranes, an unusual phenomenon concerning the action of sodium hydroxide was observed. Normally sodium hydroxide causes swelling of cellulose materials, but in the membrane it produces a shrinkage. However, even when the sample is allowed to freely mercerize, it keeps a preferential orientation (Figure 9). The shrinkage appears to be definitely associated with a crystallographic change to the mercerized form, since the concentration of sodium hydroxide must be sufficient to produce a mercerized structure before any appreciable shrinkage occurs.

If the membrane is first dried on a glass plate and then treated with sodium hydroxide, it shrinks to only about two-thirds the former width and length, with a slight increase in thickness. This process tends to destroy slightly the original selective uniplanar orientation of the dried specimen. On the other hand, both ends of a flat strip of the undried membrane were clamped to a glass plate in order to prevent the shrinkage from occurring during mercerization. This process tends to produce a selective uniaxial oriented cellulose II structure, as shown in Figure

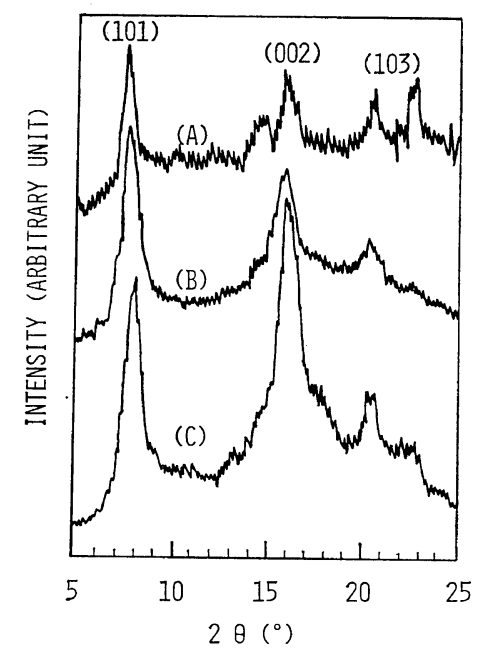

Figure 11. X-ray diffractograms of acetylated native celluloses by the reflection method: (A) acetylated Valonia; (B) acetylated bacterial; (C) acetylated ramie celluloses. 
Biosynthesis of Cellulose by Acetobacter Xylinum I.

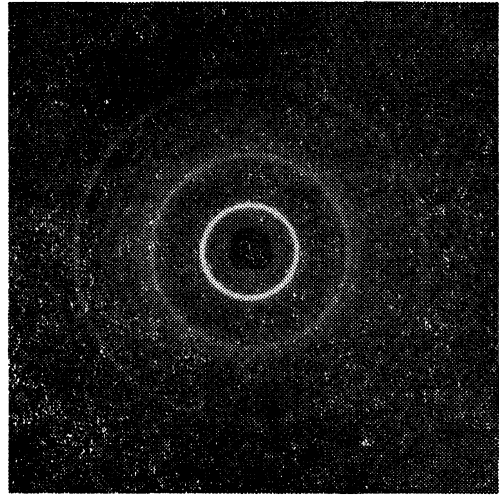

(A)

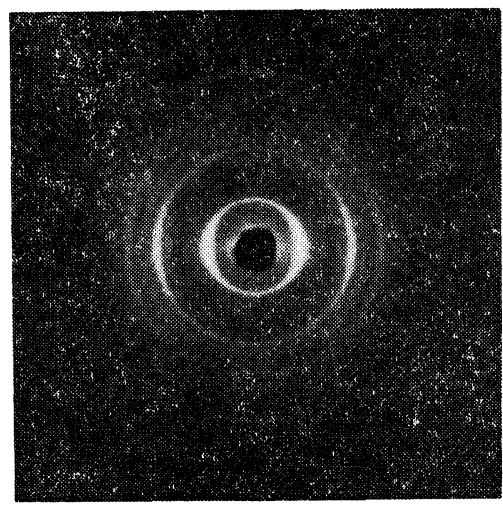

(B)

Figure 12. X-ray photographs of acetylated bacterial cellulose; X-rays (A) perpendicular to and (B) parallel to the surface of the membranes.

10. The very compact form of the dried membrane, however, makes it difficult to produce a mercerized crystalline structure. Furthermore, Valonia cellulose was the most difficult to mercerize with such a process.

Highly acetylated products were obtained from bacterial cellulose $(\mathrm{DS}=2.82)$, ramie cellulose $(\mathrm{DS}=2.97)$ and Valonia cellulose $(\mathrm{DS}=2.25)$ by the glacial acetic acid pretreatment. Heat-treatment of these triacetates was carried out with silicone oil at $210^{\circ} \mathrm{C}$ for $15 \mathrm{~min},{ }^{21}$ resulting in the sharp X-ray patterns of Figure 11. It is generally accepted that two stable polymorphic crystalline structures exist in cellulose triacetate; cellulose triacetate I and II. ${ }^{21,22,23}$ They can be distinguished from each other clearly by X-ray analysis. Acetylated bacterial, ramie and Valonia celluloses give four sharp equatorial diffractions

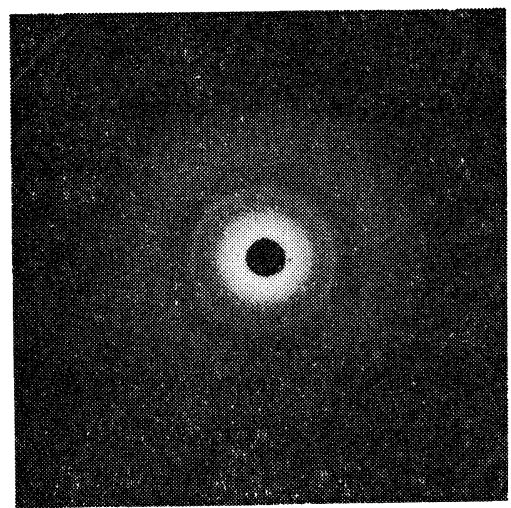

(A)

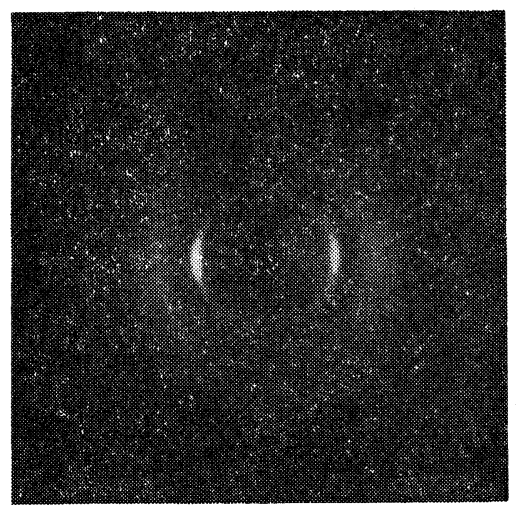

(B)

Figure 13. $\mathrm{X}$-ray photographs of nitrated bacterial cellulose; X-rays (A) perpendicular to and (B) parallel to the surface of the membranes.

at $11.5\left(2 \theta=7.7^{\circ}\right), 5.5\left(16.1^{\circ}\right), 4.3\left(20.7^{\circ}\right)$ and 3.9 $\left(22.8^{\circ}\right) \AA$. They are typical patterns of so-called triacetate I. However, the intensity ratios of peaks at 11.5 and $5.5 \AA$ for bacterial and Valonia celluloses are different from that of ramie cellulose. This suggests that a preferential orientation of crystallites in bacterial and Valonia celluloses affects the fine structures of the heterogeneously acetylated products. Figure 12 shows X-ray photographs of highly recrystallized bacterial cellulose triactate; (A) X-ray perpendicular to and (B) parallel to the flat surface of the membrane. Especially both patterns are considerably different each other in the orientation of the diffraction at $11.5 \AA$. The perpendicular pattern, is random with the (101) line present, whereas in the parallel pattern, the fiber diagram was obtained with all lines present as an intensive 
arc on the equator. It is interesting to note that the selective orientation is disturbed during the heterogeneous acetylation. The acetylated membrane is still available for the crystalline structural study of cellulose triacetate.

Figure 13 shows the X-ray photographs of nitrated bacterial cellulose reacted with $\mathrm{H}_{2} \mathrm{SO}_{4}$ $\mathrm{HNO}_{3}$ at $0^{\circ} \mathrm{C}$ for $24 \mathrm{hr}$ and then treated with hot water in an autoclave at $150^{\circ} \mathrm{C}$ for $2 \mathrm{hr}$. Both of them have the same difference as acetylated product in the intensity distribution of the lowest diffraction at $7.08 \AA$. When bacterial cellulose membranes are nitrated by three different types of acid mixture, $\mathrm{H}_{2} \mathrm{SO}_{4}-\mathrm{HNO}_{3}, \mathrm{AcOH}-$ (Ac) $)_{2} \mathrm{O}-\mathrm{HNO}_{3}$ and $\mathrm{H}_{3} \mathrm{PO}_{4}-\mathrm{HNO}_{3}$, their intensities are a little different from each other. The difference are believed to be due to the homogeneity or heterogenity resulting from the nitration reaction. The nitrated bacterial and Valonia celluloses also have a preferential orientating tendency as well as the acetylated bacterial and Valonia celluloses.

Acknowledgment. This investigation has been supported in part by a grant in aid for scientific research from the Japanese Government in 1972 and 1973.

The authors are very indebted to Professors H. Iida and M. Azuma of the Department of Bacteriology, Medical School of Hokkaido University, for their helpful suggestions in the course of this work.

\section{REFERENCES}

1. B. A. T $\phi$ nnesen and $\emptyset$. Ellefsen, Norsk Skogind., 7, 266 (1960).

2. R. St. J. Manley, Nature, 204, 1155 (1964).

3. A. J. Brown, J. Chem. Soc., 49, 432 (1886).
4. H. Hibbert, Science, 71, 419 (1930).

5. H. Mark and G. V. Susich, Z. physik. Chem., Abt. B. 4, 431 (1929).

6. P. H. Hermans, "Physics and Chemistry of Cellulose Fibers", Elsevier Publishing Company Inc., New York, N.Y., Amsterdam, London, Brussels, 1949, p 517.

7. A. Frey-Wyssling and K. Mühlethaler, Makromol. Chem., 62, 25 (1965).

8. I. Ohad, D. Danon, and S. Hestrin, J. Cell. Biol., 12, 31 (1962).

9. A. A. J. Heyn, J. Ultrastruct. Res., 26, 52 (1968).

10. K. H. Gardner and J. Blackwell, J. Polym. Sci., Part C, 36, 327 (1972).

11. I. Nieduszynski and R. D. Preston, Nature, 225, 273 (1970).

12. J. R. Colvin, "Cellulose and Cellulose Derivatives”, N. M. Bikales and L. Segal Ed., John Wiley \& Sons-Interscience, New York, N.Y., 1971, Part IV, Chapter XVI b, p 695.

13. H. J. Marrinan and J. Mann, J. Polym. Sci., 21, 301 (1956).

14. G. Honjo and M. Watanabe, Nature, 181, 326 (1958).

15. K. C. Ellis and J. O. Warwicker, J. Polym. Sci., 56, 339 (1962).

16. C. Y. Liang and R. H. Marchessault, ibid., 37, 385 (1959).

17. R. A. Jacobson, J. A. Wunderlich, and W. N. Lipscomn, Acta Cryst., 14, 598 (1961).

18. S. S. C. Chu and G. A. Jeffrey, ibid., B 24, 830 (1968).

19. D. W. Jones, J. Polym. Sci., 32, 371 (1958).

20. J. Mann and H. J. Marrinan, Trans. Farady. Sci., 52, 481 (1956).

21. M. Takai, J. Hayashi, and S. Watanabe, $J$. Polym. Sci., Part C, 23, 825 (1968).

22. K. Hess and C. Trogus, Z. Phys. Chem., B 5, 161 (1929).

23. B. S. Sprague, J. L. Riley, and H. D. Norther, Text. Res. J., 28, 275 (1958). 